\title{
Malignancy, weight loss, and the small intestinal mucosa
}

\author{
R. E. BARR $Y^{1}$ \\ From the University of Bristol, Department of Medicine, Bristol Royal Infirmary
}

SUMMARY The mucosal architecture and mucosal dynamics of the small bowel have been studied in patients with malignant disease not of the gastrointestinal tract but associated with severe weight loss. Mucosal changes in malignant disease are demonstrated by stereomicroscopy, mucosal architectural measurement, and decreased lactose utilization. Measurement of the epithelial DNA loss rate indicates, in association with mucosal measurement, that the architectural changes are caused by a hypoplasia of the epithelium. Similar findings are demonstrated in patients with profound weight loss due to other non-malignant wasting diseases. Although mucosal changes undoubtedly occur in malignant disease, the changes are not specific for malignancy and the concept of 'cancer enteropathy' is not tenable. It is suggested that mucosal changes are the effect of and not the cause of cachexia.

Excessive weight loss is well recognized as a feature of malignant disease. Anorexia almost certainly plays a part in this process, but it has also been suggested that the malignant disease may in some way affect the small bowel mucosa to produce anatomical changes and a degree of malabsorption which may contribute to the cachexia.

A few patients with carcinoma of the small intestine have been shown to have abnormalities of the jejunal mucosa (Joske, 1960; Blackwell, 1961 ; Kelly, Troup, Logan, and Terry, 1961; Girdwood, Delamore, and Williams, 1961) but these abnormalities tend to be of a minor degree and localized to the vicinity of the tumour.

However, Creamer (1964) suggested that malignant neoplasms occurring at sites distant from and not involving the gastrointestinal tract were associated with abnormalities of the mucosal architecture and disorders of absorption. Other workers have produced evidence to support this suggestion (Loehry and Creamer, 1966; Wangel and Deller, 1965; Deller, Murrell, and Blowes, 1967; Dymock, Mackay, Miller, Thomson, Gray, Kennedy, and Adams, 1967) but others have been unable to confirm these findings (Girdwood, 1964; Fischer, Rosoff, Altshuler, Thayer, and Spiro, 1965; Berndt, 1968; Klipstein and Smarth, 1969).

The question remains, therefore, does malignant

${ }^{1}$ Present address, Division of Gastroenterology, Department of Medicine, Harbor General Hospital, Torrance, and the University of California School of Medicine, Los Angeles.

Received for publication 22 April 1974. disease anywhere in the body cause changes in the small intestinal mucosa? The controversy was recently resurrected by Gilat, Fischel, Danon, and Loewenthal (1973) who postulated the existence of a 'cancer enteropathy' after finding ten instances of partial villous atrophy in a study of 82 patients with malignant disease. The purpose of this paper is to report the results of a study of this phenomenon performed on a geographically localized population of uniform ethnic origins in the years 1968-1970.

\section{Selection of patients}

Three groups of patients were studied. Group 1 consisted of patients with biopsy-proven malignant disease occurring anywhere in the body but not involving the gastrointestinal tract either primarily or secondarily. All patients in group 1 had lost a minimum of $21 \mathrm{lb}$ weight. These cases were compared with group 2, a control group of 20 normal but hospitalized patients, who were matched for age but not sex. This group was drawn from patients admitted to the Bristol Royal Infirmary for investigation of vague abdominal symptoms in whom no evidence of organic disease or weight loss could be found. Group 3 was a second 'control' population consisting of 15 patients who were ill and had lost more than $28 \mathrm{lb}$ in weight for reasons other than malignant or gastrointestinal disease. This group included patients suffering from rheumatoid arthritis, SLE, endocrine disease, extensive skin disease, anorexia nervosa, heart failure, and chronic renal failure. 
In addition, the mucosal morphology of three comparable groups was studied at necropsy. The first necropsy group consisted of 23 patients dying of extensive malignant disease not affecting the gastrointestinal tract. The second group was assumed to be normal controls and consisted of 36 patients coming to necropsy after sudden death, ie, after illnesses lasting less than 48 hours, and included exsanguination from gastrointestinal haemorrhage, ruptured ectopic pregnancy, acute myocardial infarction, road traffic accidents, dissecting aneurysms, and similar sudden catastrophes. The third postmortem group consisted of 52 patients dying after illnesses of more than three days' duration with a weight loss of $28 \mathrm{lb}$ or greater. The causes of death in this group were other than malignant or gastrointestinal disease.

\section{Methods}

\section{JEJUNAL BIOPSIES}

Peroral jejunal biopsies were obtained using a Watson capsule screened to a point in the jejunum approximately 6 in. distal to the ligament of Treitz. The stereomicroscopic features of each biopsy were recorded photographically before each specimen was processed for histological section. The photographs were then coded so that the patient's name and diagnosis were unknown in the subsequent assessment. The mucosal architecture of jejunal biopsies is often described according to the dominant mucosal feature, eg, convolutions. Although this causes no difficulty in many biopsies, it involves a subjective assessment of the features which is not always easy to make. In order to overcome this problem we used a grading system defined strictly so as to eliminate the need for a subjective assessment. The architectural features were graded according to the presence of the following features.

Grade 1

The presence of cylindrically shaped villi only. Grade 2

The presence of more than one leaf-shaped villus, a leaf being defined as having a long diameter greater than twice the short diameter.

Grade 3

The presence of more than one ridge-shaped villus, a ridge being defined as havinga long diameter greater than 15 times the shorter diameter.

Grade 4

The presence of more than one convolution, a convolution being defined as having a ridge with a minimum of two angulations of 90 degrees or less.

After photography, the jejunal biopsy was gently applied to a piece of flat card, luminal surface uppermost, and fixed by floating (specimen side downwards) on $10 \%$ neutral buffered formol saline. The specimen is fixed in a flat position and does not curl enabling $5 \mu$ sections to be prepared cutting the specimen exactly perpendicularly. The sections were then coded so that the patient's name and diagnosis were unknown during assessment.

Using a micrometer eyepiece, the total mucosal thickness was measured from the muscularis mucosa to the tip of a longitudinally sectioned villus in as many places as were suitable in several non-serial sections, a minimum of 20 measurements being taken. Measurements were only taken where the whole of a crypt and adjacent villus were sectioned along the whole of their length thus minimizing errors due to oblique sectioning. The height of the villus was also measured, from crypt neck to tip, so that the ratio villus height: total mucosal thickness could then be calculated. This ratio is then an inverse indication of crypt depth which is easier and more accurate to determine than by direct measurement.

In a preliminary study six normal biopsies and six biopsies from patients with coeliac disease were measured on 10 separate occasions making a minimum of 20 observations per biopsy on each occasion. For total mucosal thickness, the 10 results for each specimen varied from their mean by only $2 \%( \pm 1 \cdot 3)$ for normals and $1.8 \%( \pm 1.3)$ for patients with coeliac disease.

\section{NECROPSY MUCOSAL SPECIMENS}

Intestinal mucosa was obtained at necropsy from a site 6 in. distal to the ligament of Treitz, pinned flat, without stretching, on small pieces of cork and then allowed to autolyse overnight in isotonic saline at room temperature. The specimen was then fixed in $10 \%$ formalin and the autolysed epithelium washed off with isotonic saline before being dehydrated in ascending concentrations of alcohol and stained with $5 \%$ eosin. This renders visible the antemortem mucosal architecture (Loehry and Creamer, 1966). Using this method, good visualization of the mucosal architecture was easily obtained up to five days after death in refrigerated cadavers (fig 1). The mucosal architecture was then graded in the same way as was the peroral jejunal biopsy specimens.

Study of mucosa before and after autolysis in operative specimens in five cases indicated that the grading of a specimen was unaffected by the autolytic process.

\section{LACTOSE UTILIZATION TEST}

Lactose utilization was measured by the method of Salmon, Read, and McCarthy (1969). Patients were studied after an overnight fast and remained at rest throughout. Five hundred $\mathrm{ml}$ of $10 \%$ lactose solution containing $5 \mu \mathrm{Ci}$ lactose-1 ${ }^{14} \mathrm{C}$ was given by mouth. In the presence of intestinal lactase, the 


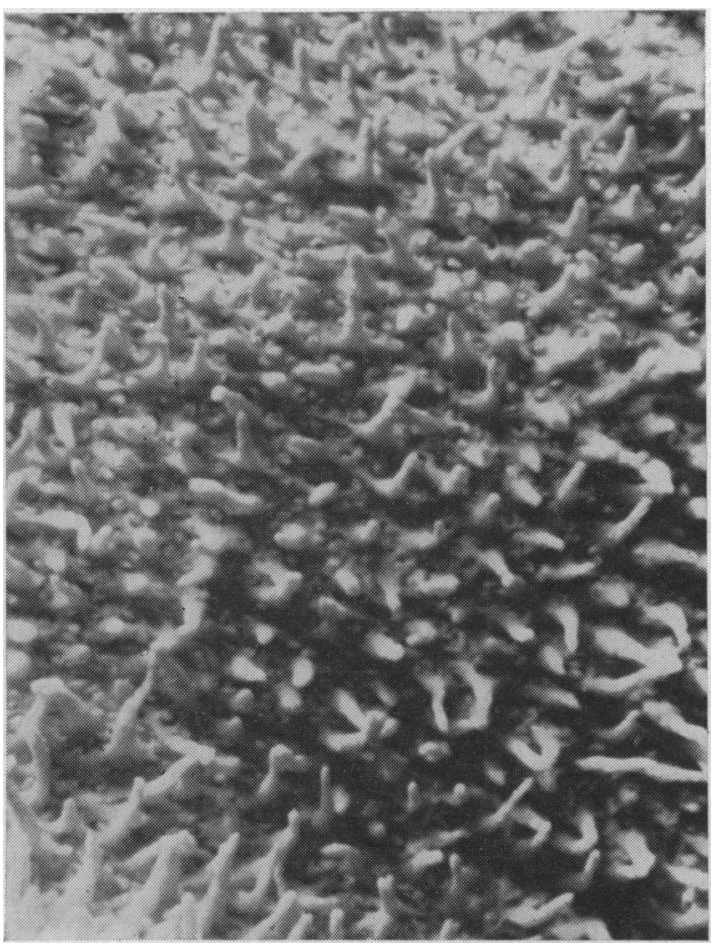

Fig 1 Necropsy preparation (grade I) normal cylindrical villi only. The villi appear thin and sparse because the epithelium is washed away after autolysis leaving only the 'skeleton' of the lamina propria. The debrisfilled crypt orifices can be seen between the villi.

lactose is hydrolysed and absorbed as glucose and galactose which are metabolized and the ${ }^{14} \mathrm{C}$ is excreted as carbon dioxide which is collected at hourly intervals in hyamine and estimated by liquid scintillation counting. The rate at which the ingested ${ }^{14} \mathrm{C}$ is excreted as radiocarbon dioxide per hour is then calculated.

\section{EPITHELIAL CELL LOSS RATE}

The DNA loss rate from the small intestinal mucosa was measured using the technique of Croft, Loehry, Taylor, and Cole (1968). We have studied the technique of Croft et al extensively and shown it to give reproducible results in our hands under specified experimental conditions (Barry, 1971).

The DNA loss rate was measured on three separate occasions in three volunteers and in one further volunteer the loss rate was measured twice. The percentage variation of the individual loss rate measurements from their mean is shown in table $\mathrm{I}$.

The mean variation from the mean was $6.8 \%$ ( \pm 4.4) indicating that this method is surprisingly reproducible in any one individual.

\begin{tabular}{|c|c|c|c|}
\hline \multirow[t]{2}{*}{ Patient } & \multicolumn{3}{|c|}{ Percentage Variation from Mean } \\
\hline & 1st Estimation & 2nd Estimation & 3rd Estimation \\
\hline $\begin{array}{l}\text { A } \\
\mathbf{B} \\
\mathbf{C} \\
\mathbf{D}\end{array}$ & $\begin{array}{l}1.8 \\
5.1 \\
0\end{array}$ & $\begin{array}{r}9 \cdot 1 \\
15.4 \\
6.8 \\
4 \cdot 4\end{array}$ & $\begin{array}{r}7 \cdot 3 \\
10 \cdot 3 \\
8 \cdot 1\end{array}$ \\
\hline
\end{tabular}

Table I Reproducibility of DNA loss rate measurement

\section{Results}

Table II indicates the number of patients in each group studied by the methods described.

\section{FRESH PERORAL BIOPSIES}

The incidence of mucosal architectural features is given in table III.

The distribution of the mucosal architectural features is shown in figure 2 . The incidence of convolutions (grade 4) is unexpected since most workers regard this feature in jejunal biopsies in a western civilization as probably abnormal. This incidence may reflect the method of selection of the 'normal' population who, although no organic disease could be found, were hospital inpatients and, therefore, symptomatic. Other workers have found a similar incidence of convoluted biopsies but their patients were less rigidly selected than those described here (Marks and Schuster, 1970).

When the incidence of the various mucosal grades is compared (fig 2), it can be seen that the distribution histograms for malignant disease and for other illnesses are displaced to the right when compared with normal controls, ie, there is a greater incidence of ridges and convolutions in these two groups and

\begin{tabular}{llll}
\hline Group & \multicolumn{3}{l}{ Number of Patients } \\
\cline { 2 - 4 } & $\begin{array}{l}\text { Jejunal } \\
\text { Biopsy }\end{array}$ & $\begin{array}{l}\text { DNA Loss } \\
\text { Rate }\end{array}$ & $\begin{array}{l}\text { Lactose } \\
\text { Utilization }\end{array}$ \\
\hline Normal controls & 20 & 17 & 11 \\
Malignant disease & 32 & 13 & 19 \\
Wasting illnesses & 15 & 13 & 6 \\
\hline
\end{tabular}

Table II Number of patients grouped by method of investigation

\begin{tabular}{llllll}
\hline & No. of Patients & \multicolumn{4}{l}{ Grade } \\
\cline { 3 - 6 } & & 1 & 2 & 3 & 4 \\
\hline Normal controls & 20 & $15 \%$ & $70 \%$ & $5 \%$ & $10 \%$ \\
Malignant disease & 32 & $9 \%$ & $44 \%$ & $34 \%$ & $13 \%$ \\
Wasting illness & 15 & 0 & $33 \%$ & $40 \%$ & $27 \%$ \\
\hline
\end{tabular}

Table III Incidence of mucosal features in fresh peroral biopsies 


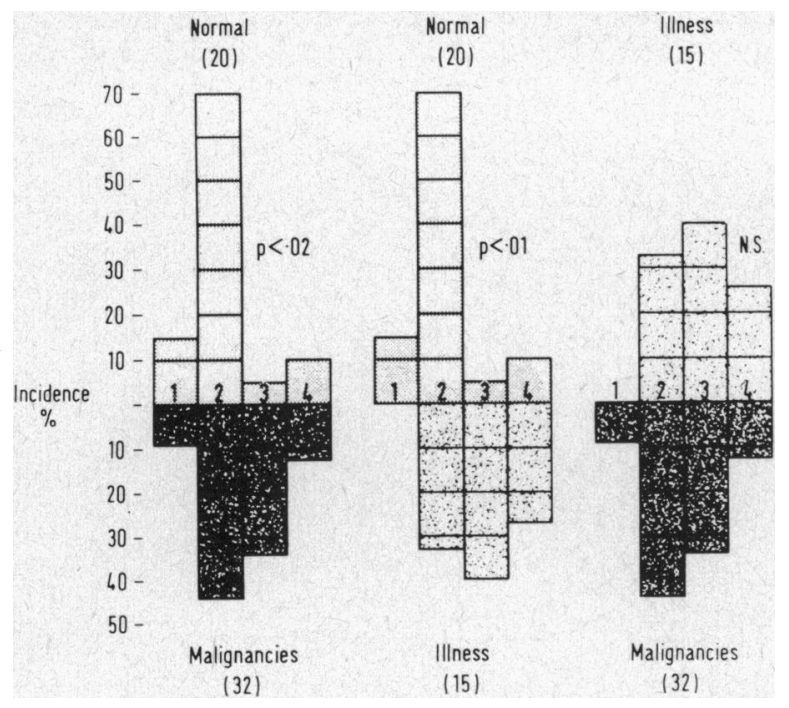

Fig 2 The mucosal architecture in malignant disease is significantly different from normal. The distribution curve shows a shift to the right, a low incidence of grades 1 and 2, and a high incidence of grades 3 and 4. The same changes are found in other wasting illnesses.

relatively fewer biopsies which may be considered definitely normal. Statistical analysis of the difference between the incidence of the individual grades using the standard $\chi^{2}$ test with Yates' correction reveals no significant difference. This is probably because of the small numbers of patients available for study. However, larger numbers for analysis may be obtained by dividing the biopsies into two groups: (1) those which are definitely normal (grades 1 and 2) and (2) those which are not definitely normal (grades 3 and 4). The difference between the normal group of patients and those with malignant disease now becomes even more obvious and is significant statistically at the level $0.02>P>0.01$.

Similarly for illnesses other than malignant disease, the incidence of definitely normal biopsies (grades 1 and 2) is less than normal at $33 \%$ while the incidence of grades 3 and 4 is greater than normal at $67 \%$. This difference is significant at the level $P<0.01$.

\section{NECROPSY SPECIMENS}

The incidence of mucosal architecture features is shown in table IV and figure 3. The difference between the normal control population (sudden death) and the findings in other wasting illnesses when analysed as described above is significant at the level $P<0.01$.

The incidence of definitely normal biopsies (grades 1 and 2) is $61 \%$ for malignant disease compared with $88 \%$ in the normal controls, and the incidence of grades 3 and 4 is twice normal. This does not, however, reach the level of statistical significance. Since

\begin{tabular}{llllll}
\hline & No. of Patients & \multicolumn{4}{l}{ Grade } \\
\cline { 3 - 6 } & & 1 & 2 & 3 & 4 \\
\hline Sudden death & 36 & $33 \%$ & $50 \%$ & $17 \%$ & 0 \\
Malignant disease & 23 & $9 \%$ & $52 \%$ & $30 \%$ & $9 \%$ \\
Wasting illness & 52 & $12 \%$ & $37 \%$ & $29 \%$ & $23 \%$ \\
\hline
\end{tabular}

Table IV Incidence of mucosal features in postmortem specimens

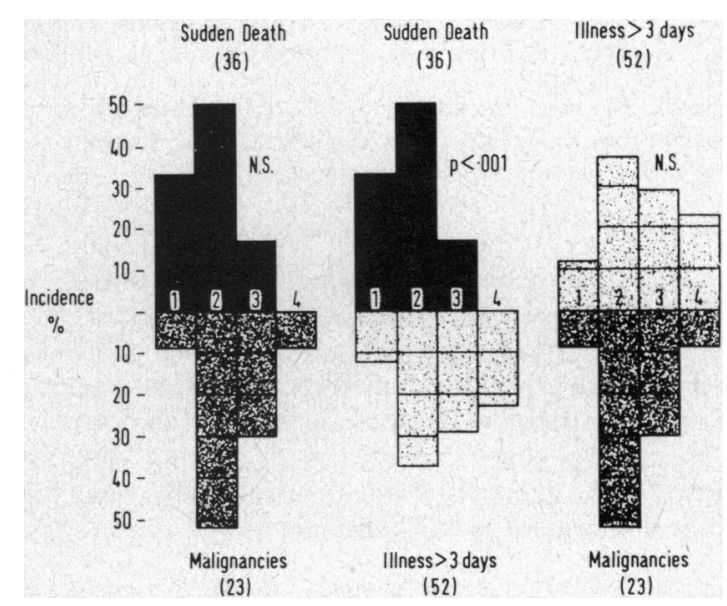

Fig 3 There is a highly significant difference between the mucosal architecture in normal controls (the sudden death group) and that in wasting illnesses. A very similar trend is shown to occur in malignant disease but does not reach the level of statistical significance with the numbers available 
the trend is identical it may be that the statistical result is a consequence of the relative paucity of patients available for study.

MUCOSAL ARCHITECTURAL MEASUREMENTS Jejunal biopsies from 19 normal controls, 27 patients with malignant disease, and 15 patients with wasting illness were suitable for measurement. The results are shown in figure 4.

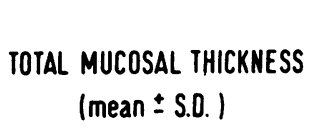

VILLOUS HEIGHT I

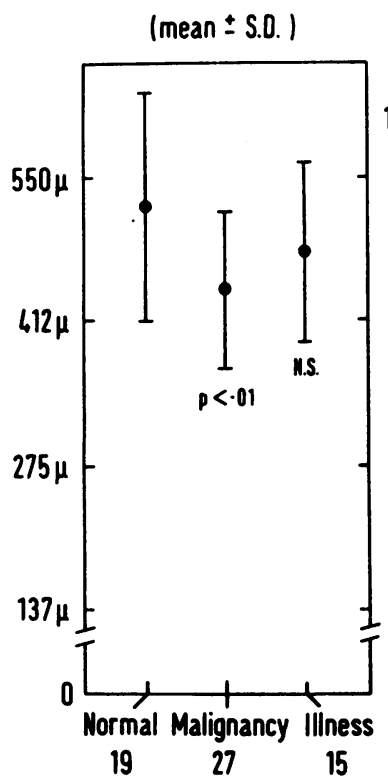

MUCOSAL THICKNESS

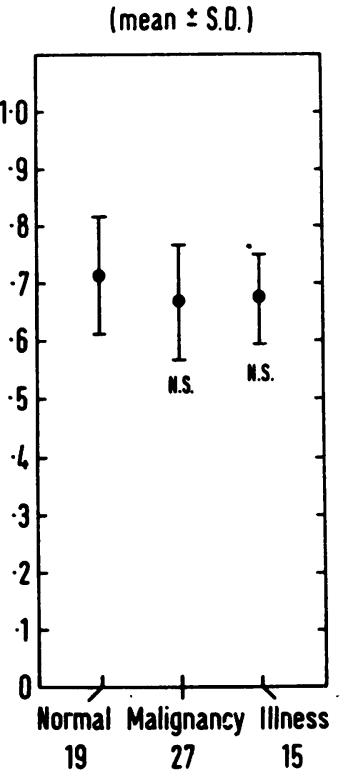

Fig 4 The total mucosal thickness in malignant disease is significantly less than normal, but the villus height: mucosal thickness ratio is unchanged.

The mean mucosal thickness in normal controls is $522( \pm 110) \mu$. The mucosal thickness in patients with malignant disease was reduced at $443( \pm 72) \mu$. Using Student's $t$ test this difference is significant at $P<0.01$. A similar decrease in mucosal thickness is observed in those patients with wasting diseases other than malignancy but this does not reach the level of statistical significance.

\section{LACTOSE UTILIZATION TEST}

The results are shown in fig 5 , in which are plotted the mean hourly excretion rates for patients with malignant disease and normal controls.

The excretion rate curve for the normal controls corresponds closely to that found by Salmon et al

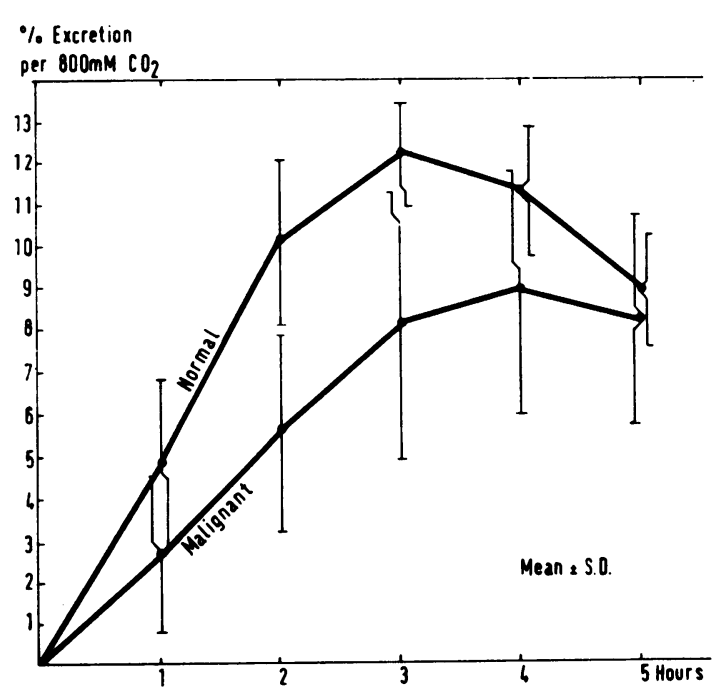

Fig 5 There is a clear difference between the excretion rates in malignancy and in normal controls indicating a decreased rate of lactose absorption in malignant disease (wasting illness group omitted for clarity).

(1969). There is a marked difference between the normal curve and that found in malignant disease. The individual values from which the means are calculated are distributed binomially so that it is possible to compare the excretion rates for each group in any one hour by means of a paired $t$ test. Using this evaluation, the difference between the normal and malignant patient's excretion rates is highly significant at one to four $\mathrm{hr}$ after ingestion of lactose $(P<0.001)$.

\section{MUCOSAL DNA LOSS RATE}

The DNA loss rate of the intestinal mucosa in the three groups of patients described is shown in table V.

The mean DNA loss rate in the group of normal controls is $56.7( \pm 18 \cdot 1) \mathrm{m} \mu \mathrm{g}$-atoms of DNA phosphorus per $5 \mathrm{~cm}$ bowel per minute. The mean DNA loss rate in the group of patients with malignant disease is decreased at $30.8( \pm 18.9)$ and is also decreased at $28.3 \pm 17.9$ ) in the third group of patients with other wasting diseases. The differences are significant at the level $P<0.001$.

Thus the epithelial cell (DNA) loss rate from the intestinal mucosa is decreased in patients with malignant and other wasting diseases. Assuming that there is a dynamic equilibrium between the rates of epithelial cell production by the crypts and their loss from the villi-as there must be in order to maintain the integrity of the mucosa - then the epithelial cell turnover is likely to be reduced also. This implies that the 


\begin{tabular}{|c|c|c|c|}
\hline \multirow[t]{2}{*}{ Patient } & \multicolumn{3}{|c|}{ DNA Loss Rate (mug-atoms $P / 5 \mathrm{~cm} /$ minute) } \\
\hline & Normal & Malignant & Illness \\
\hline 1 & 56 & 21 & 58 \\
\hline 2 & 56 & 27 & 15 \\
\hline 3 & 50 & 18 & 51 \\
\hline 4 & 59 & 20 & 28 \\
\hline 5 & 41 & 9 & 14 \\
\hline 6 & 33 & 33 & 14 \\
\hline 7 & 43 & 65 & 22 \\
\hline 8 & 47 & 25 & 10 \\
\hline 9 & 42 & 57 & 41 \\
\hline 10 & 74 & 31 & 57 \\
\hline 11 & 69 & 6 & 8 \\
\hline 12 & 80 & 27 & 20 \\
\hline 13 & 76 & 61 & 30 \\
\hline 14 & 71 & & \\
\hline 15 & 47 & & \\
\hline 16 & 27 & & \\
\hline 17 & 93 & & \\
\hline Mean (SD) & 56.7 (18) & 30.8 (19) & $28 \cdot 3(18)$ \\
\hline
\end{tabular}

Table V DNA loss rate

architectural changes demonstrated above in the jejunum of patients with malignant disease are caused by a hypoplasia of the mucosa.

\section{Discussion}

The findings in the peroral jejunal biopsy specimens indicate that weight loss in malignant disease is associated with changes in the mucosal architecture of the small bowel. The same changes are demonstrated in the necropsy material but not to the same extent. The difficulty with statistical analysis caused by small numbers cannot be overcome by pooling the data from the two parallel parts of the study (necropsy and fresh peroral biopsies) because they were performed on quite different populations and by different techniques. For example, the 'normal' population from whom the peroral biopsies were obtained is less likely to be entirely normal than is the comparable group of sudden death patients who were entirely asymptomatic until the catastrophe causing their death. Similarly, patients who were ill but well enough to submit to jejunal biopsy may not be comparable with patients dying after prolonged illness.

The line of distinction between a 'normal' stereomicroscopic appearance and an 'abnormal' one is not easily discerned and for this reason the description 'abnormality' has been avoided in this communication. There is no doubt, however, that mucosal changes have been demonstrated in that the incidence of convolutions and ridge formations in malignant disease is much higher than in the normal control population. But these same mucosal changes are shown to occur in diseases other than malignancy in which comparable weight loss has occurred.
Wasting illness appeared to have a more marked effect on intestinal appearance than malignancy but this group did lose more weight, ie, a mean weight loss of $28 \mathrm{lb}$ compared with $21 \mathrm{lb}$.

There have been several publications suggesting that small bowel function in malignant disease is abnormal (Dymock et al, 1967; Klipstein and Smarth, 1969; Dymock, 1966; Danon and Gilat, 1968). There is, however, no satisfactory single test of small bowel function and many of the routine tests of absorption, eg, folate absorption tests, are extremely difficult to interpret in the presence of malignant disease. The lactose utilization test may be regarded as an index of small bowel function but suffers from the same disadvantages inherent in any test of carbohydrate absorption. The rise in blood sugar is dependent not only on the rate of absorption but also on the rate of hydrolysis and rate of clearance from the blood. But the lactose utilization test gives a cumulative record of the absorbed radiocarbon and is, therefore, less influenced by the rate of clearance from the blood. However, the test is used here as a measure of the anatomical integrity of the mucosa. It has been shown that mucosal lactase levels, with which the lactose utilization test correlates well (Salmon et al, 1969), are a sensitive index of damage to the mucosa in that this enzyme is the first to disappear and the last to reappear when the mucosa is subjected to insult (Sheehy and Anderson, 1965). Because of the localization of the enzyme lactase to the epithelial cell brush border, the amount of available lactase is proportional to the surface area of the intestinal villi. Thus, it seems likely that the very real reduction in the rate of lactose absorption demonstrated in this study in patients with malignant and other wasting disease is a consequence of the structural changes already demonstrated rather than a functional abnormality, ie, it may be indicative of a decreased surface area of mucosa.

Histological examination of all the jejunal biopsies has failed to reveal any evidence of epithelial cytological damage. Within the limits of the best light microscope, all the epithelial cells are healthy looking columnar cells with a normal brush border. Specific alactasia, however, frequently occurs without brush border damage. The expected incidence of hypolactasia in the normal English population is unknown but has been placed as high as $30 \%$ (McMichael, Webb, and Dawson, 1966). This figure was derived from the investigation of symptomatic hospital inpatients and cannot be regarded as indicative of the normal population, particularly as secondary hypolactasia is frequently encountered (Gudmand-Höyer, Dahlqvist, and Jarnum, 1969). The incidence of alactasia in a large series of American 
volunteers was $6 \%$ (Newcomer and McGill, 1967), and this is similar to an incidence of $2.6 \%$ to $6.6 \%$ in Denmark (Gudmand-Höyer et al, 1969). On the basis of the evaluation of Salmon and Read (1969) of the lactose utilization test, five $(26 \%)$ of the cases of malignant disease may be classed as having alactasia. This would appear to be an extraordinarily high incidence when compared with the Danish and American figures. It seems unlikely, therefore, that the decreased rate of lactose utilization by the malignant patients may be explained on the basis of the chance inclusion of random cases of specific alactasia, especially since the exclusion of these five cases from the analysis still results in a decreased mean excretion rate in the malignant disease group.

Further possible explanations of the lower lactose utilization rate in the patients with malignant disease may be a decreased rate of gastric emptying which would decrease the apparent rate of lactose utilization by reducing the rate at which the sugar is presented to the small intestinal mucosa or increased degradation of brush border enzymes associated with 'starvation' (Alpers and Kinzie, 1973). No formal tests of gastric emptying were performed in this group of patients, but it is quite conceivable that the patients with malignant disease, all of whom had lost more than $21 \mathrm{lb}$ in weight and were markedly anorexic, may have a decreased rate of gastric emptying.

It is now well established that the small bowel epithelial cells are produced by mitotic division in the crypts only, and then migrate to the villi where they are subsequently shed. The mucosal architecture depends entirely on the balance between cell production in the crypts and their loss from the villi (Loehry and Creamer, 1969). It may be expected, therefore, that changes in mucosal architecture demonstrated here may be accompanied by changes in the epithelial cell turnover rate. There are several methods of estimating cell turnover but all suffer from some disadvantages when applied to man. The most accurate measure of mucosal turnover is obtained from observation by autoradiography of cells labelled with tritiated thymidine during the S-phase of mitosis. Because of the potential hazards of introducing such a radioactive label directly into the nuclei of dividing cells, such a technique could never be justified in man although it has been used in a few patients in the terminal stages of disease (MacDonald, Trier, and Everett, 1964). The DNA loss rate gives only the crudest estimate of epithelial cell desquamation but is simple to perform, safe, and reproducible.

The rate of epithelial cell turnover is reflected to some extent in the relative geometric proportions of the various regions of the histological section of the jejunal biopsy (Creamer, 1965). For example, a hostile luminal environment such as occurs in hyperacidity or infestation results in excessive epithelial cell desquamation and a consequent adaptive hypertrophy of the crypts. Thus, the mucosal architectural changes found in these circumstances are characterized by a normal mucosal thickness and decreased crypt : villus ratio. The increased epithelial cell output from the crypts maintains the mucosal thickness. This process is seen to an extreme degree in coeliac disease when the crypt depth comes to occupy the whole of the mucosal thickness. Conversely, in a hypoplastic mucosa such as occurs during the administration of cytotoxic drugs, there is a decreased rate of cell production by the crypts which, in the presence of a normal rate of cell loss from the villi, results in a fall in mucosal thickness but with the maintenance of a relatively normal crypt : villus ratio. Thus the findings illustrated in figure 4 , which demonstrate a significantly decreased mucosal thickness in malignant disease but a normal crypt : villus ratio, suggest a hypoplastic mucosa and supports the finding of a decreased epithelial cell turnover rate as measured by the DNA loss rate method.

The mucosal measurements in wasting disease other than malignancy are not significantly different from those in normal controls. However, architectural changes are demonstrated in this group of patients and occur to the same or perhaps even a greater extent than in the malignant disease group (figs 2 and 3). Furthermore, they show the same diminution in DNA epithelial cell loss rate as do patients with malignant disease. There can be no doubt, therefore, that mucosal changes are associated with malignant disease but that these changes appear to occur in any patient with cachexia from whatever cause and there seems no reason to regard this 'enteropathy' as specific to malignancy.

Several factors are know to influence the epithelial cell turnover rate of the intestinal mucosa other than the obvious affects of radiation and cytotoxic drugs. The effects of a hostile luminal environment have been commented upon already. Dubos (1966) has demonstrated that animals raised in a germ-free environment have abnormally long villi and short crypts suggestive of a decreased rate of epithelial cell turnover, and it has been shown (Kenworthy and Allen, 1966) that placing germ-free pigs into a conventional environment reverses these findings. It is clear, however, that epithelial cell turnover may be influenced by other factors which do not in themselves appear to influence the luminal environment of the cells. Protein malnutrition (Deo and Ramalingaswami, 1965), starvation (Goldsmith, 1973), and severe folate deficiency (Hermos, Adams, Liu, Sullivan, and Trier, 1971) have been shown to 
decrease epithelial cell turnover whereas resection of the small bowel in animals is associated with an increased epithelial cell turnover in the remaining small bowel (Loran and Althausen, 1960; Dowling and Gleeson, 1973). The mechanism producing the hypoplastic mucosa demonstrated in the study presented here is entirely unknown. It may be that, because of its very high cell turnover rate, the epithelium of the small bowel is particularly susceptible to the relative lack of nutritional factors such as may occur in starvation or severe cachexia. The reports of malabsorption following extreme attempts to lose weight (Pittman, 1966) and the finding of grade 3-4 biopsies in all of three cases of anorexia nervosa in the present study would tend to support this hypothesis. Furthermore, the effect of the luminal nutrition on the epithelial cell turnover rate has been demonstrated in animals. Intestinal hyperplasia has been demonstrated in the remaining small bowel mucosa following partial intestinal resection (Dowling and Booth, 1967; Gleeson, Cullen, and Dowling, 1972) and it has been suggested that this hyperplasia may be the result of the exposure of the remaining small bowel mucosa to an increased amount of nutrients in the bowel lumen to which it was not previously exposed. Conversely, deprivation of luminal nutrition such as occurs in bypassed small bowel segments is associated with mucosal hypoplasia (Gleeson et al, 1972; Rieken, Menge, Bloch, and Schaumloffel, 1970). Since the patients in this study were anorexic and selected for study because of their profound weight loss it would appear that the mucosal changes demonstrated may well be a consequence of their anorexia and the associated decrease in 'luminal nutrition'.

In conclusion, it has been shown in this study that mucosal architectural changes do indeed occur in malignant disease and that these changes are likely to have been caused by hypoplasia of the mucosa with a decreased epithelial cell turnover time. There is, however, no reason to regard this finding as a specific 'cancer enteropathy' as suggested by Gilat et al (1972) since precisely the same findings occur in patients who are ill and losing weight from other causes. Furthermore, the epithelial changes may well be the result of the patients' weight loss and not the cause of it.

This work was supported by the Medical Research Council during the author's tenure of a junior fellowship. The author thanks the council for financial support and Victoria M. Adkins for secretarial assistance.

\section{References}

Alpers, D. H., and Kinzie, J. L. (1973). Regulation of small intestinal protein metabolism. Gastroenterology, 64, 471-496.
Barry, R. E. (1971). The effect of malignant disease on the small intestinal mucosa. MD Thesis, University of Bristol.

Berndt, H. (1968). Malabsorption in cancer of and outside the bowel . Digestion, 1, 305-310.

Blackwell, J. B. (1961). Malabsorption in the presence of primary carcinoma of the small bowel. Gut, 2, 377.

Creamer, B. (1964). Malignancy and the small intestinal mucosa. Brit. med. J., 2, 1435-1436.

Creamer, B. (1965). The dynamics of the small intestinal mucosa. In Recent Advances in Gastroenterology, edited by J. Badenoch and B. N. Brooke. Churchill, London.

Croft, D. N., Loehry, C. A., Taylor, J. F. N., and Cole, J. (1968). DNA and cell loss from the normal small intestinal mucosa. Lancet, 2 70-73.

Danon, J., and Gilat, T. (1968). Absorption and enzyme studies in patients with malignancy. Digestion, 1, 316

Davidson, J. N., and Leslie, I. (1950). A new approach in the biochemistry of growth and development. Nature (Lond.), 165, 49-53.

Deller, D. J., Murrell, T. G. C., and Blowes, R. (1967). Jejunal biopsy in malignant disease. Aust. Ann. Med., 16, 236-241.

Deo, M. G., and Ramalingaswami, V. (1965). Reaction of the small intestine to induced protein malnutrition in Rhesus monkeys: a study of cell population kinetics in the jejunum. Gastroenterology, 49, 150-157.

Dowling, R. H., and Booth, C. C. (1967). Structural and functional changes following small intestinal resection in the rat. Clin. Sci., 32, 139-149.

Dowling, R. H., and Gleeson, M. H. (1973). Cell turnover following small bowel resection and by-pass. Digestion, 8, 176-190.

Dubos, R. (1966). The microbiota of the gastrointestinal tract. Gastroenterology, 51, 868-874.

Dymock, I. W. (1966). Enteropathy in malignant disease. Brit. J. Cancer, 20, 236-238.

Dymock, I. W., Mackay, N., Miller, V., Thomson, T. J., Gray, B. Kennedy, E. H., and Adams, J. F. (1967). Small intestinal function in neoplastic disease. Brit. J. Cancer, 21, 505-511.

Fischer, R. A., Rosoff, B. M., Altshuler, J. H., Thayer, W. R., Jr., and Spiro, H. M. (1965). Disacchariduria in malignant disease. Cancer (Philad.), 18, 1278-1284.

Gilat, T., Fischel, B., Danon, J., and Loewenthal, M. (1973). Morphology of small bowel mucosa in malignancy. Digestion, 7 , 147-155.

Girdwood, R. H. (1964). Malignancy and the small intestinal mucosa. Brit. med. J., 2, 1592.

Girdwood, R. H., Delamore, I. W., and Williams, A. W. (1961). Jejunal biopsy in malabsorptive disorders of the adult. Brit. med. J., 1, 319-323.

Gleeson, M. H., Cullen, J., and Dowling, R. H. (1972). Intestinal structure and function following small bowel by-pass in the rat. Clin. Sci., 43, 731-732.

Goldsmith, D. P. S. (1973). Changes in desquamation rate of jejunal epithelium in cats during fasting. Digestion, 8, 130-141.

Gudman-Höyer, E., Dahlqvist, A., and Jarnum, S. (1969). Specific small intestinal lactase deficiency in adults. Scand.J. Gastroent., 4, 377-386.

Hermos, J., Adams, W., Liu, Y., Sullivan, L., and Trier, J. (1971). The intestinal lesion in folate deficiency. Clin. Res., 19, 394.

Kenworthy, R., and Allen, W. D. (1966). The significance of Escherichia coli to the young pig. J. comp. Path., 76, 31-44.

Klipstein, F. A., and Smarth, G. (1969). Intestinal structure and function in neoplastic disease. Amer. J. dig. Dis., 14, 887-899.

Loehry, C. A., Creamer, B. (1966). Post-mortem study of smallintestinal mucosa. Brit. med. J., 1, 827-829.

Loehry, C. A., and Creamer, B. (1969). Three dimensional structure of the rat small intestinal mucosa related to mucosal dynamics. Gut, 10, 112-120.

Loran, M. R., and Althausen, T. L. (1960). Cellular proliferation of intestinal epithelia in the rat two months after partial resection of the ileum. J. biophys. biochem. Cytol., 7, 667-672.

MacDonald, W. C., Trier, J. S., and Everett, N. B. (1964). Cell proliferation and migration in the stomach, duodenum and rectum of man: radioautographic studies. Gastroenterology, 46, 405-417.

McMichael, H. B., Webb, J., and Dawson, A. M. (1966). Jejunal disaccharidases and some observations on the cause of lactase deficiency. Brit. med. J., 2, 1037-1041.

Marks, J., and Shuster, S. (1970). Small intestinal mucosal abnormalities in various skin diseases - fact or fantasy? Gut, 11, 281-291. 
Newcomer, A. D., and McGill, D. B. (1967). Disaccharidase activity in the small intestine; prevalence of lactase deficiency in 100 healthy subjects. Gastroenterology, 53, 881-889.

Pittman, F. E. (1966). Primary malabsorption following extreme attempts to lose weight. Gut, 7, 154-158.

Rieken, E. O., Menge, H., Bloch, R., and Schaumloffel, E. (1970). Transport studies, morphological, histochemical and morphometric findings in the excluded jejunal loop in the rat. In Advance Abstracts of 4th World Congress of Gastroenterology,
12-18 July 1970 , edited by P. Riis, P. Anthonisen, and $H$. Baden, p. 448. Danish Gastroenterological Association, Copenhagen.

Salmon, P. R., Read, A. E., and McCarthy, C. F. (1969). An isotope technique for measuring lactose absorption. Gut, 10, 685-689.

Sheehy, T. W., and Anderson, P. R. (1965). Disaccharidase activity in normal and diseased small bowel. Lancet, 2, 1-4.

Wengell, A. G., and Deller, D. J. (1965). Malabsorption syndrome associated with carcinoma of the bronchus. Gut, 6, 73-76.

\section{The June 1974 Issue}

\section{THE JUNE 1974 ISSUE CONTAINS THE FOLLOWING PAPERS}

Short-term course and prognosis of Crohn's disease F. T. de DOMBAL, I. L. BURTON, SUSAN E. CLAMP, AND J. C. GOLIGHER

Functional differentiation of human jejunum and ileum: A comparison of the handling of glucose, peptides, and amino acids D. B. A. SILK, JOAN P. W. WEBB, ANNETTE E. LANE, M. L. CLARK, AND A. M. DAWSON

Coeliac disease during the teenage period: The value of serial serum folate estimations D. G. WEIR, AND D. O'B. HOURIHANE

The jejunal cellular infiltrate in coeliac disease complicated by lymphoma R. FERGUSON, P. ASQUITH, AND W. T. COOKE

The effect of metoclopramide on gastric emptying of solid meals B. D. HANCOCK, E. BOWEN-JONES, R. DIXON, I. W. DYMOCK, AND D. J. COWLEY

Increased serum immunoglobulin levels following portacaval shunt in the normal rat M. KERAAN, O. L. MEYERS, G. H. C. ENGELBRECHT, ROSEMARY HICKMAN, S. J. SAUNDERS, AND JOHN TERBLANCHE

The epidemiology of primary biliary cirrhosis: A survey of mortality in England and Wales A. N. HAMLYN AND S. SHERLOCK
ABO blood groups, Rhesus negativity, and primary biliary cirrhosis A. N. HAMLYN, J. S. MORRIS, AND S. SHERLOCK

Effects of haemoperfusion through charcoal or XAD-2 resin on an animal model of fulminant liver failure M. J. WESTON, B. G. GAZZARD, B. H. BUXTON, J. WINCH, A. L. MACHADO, H. FLAX, AND ROGER WILLIAMS

The organic matrix of gallstones D. JUNE SUTOR AND SUSAN E. WOOLEY

\section{Technique}

Use of a duodenal capsule for localization of upper gastrointestinal haemorrhage RICHARD R. BABB AND CHARLES B. BEAL

Progress report Peptide absorption in man D. B. A. SILK

Progress report Radioimmunoassay of intestinal hormones S. R. BLOOM

British Society for Digestive Endoscopy

Notes and activities

Notes on books

Copies are still available and may be obtained from the PUBLISHING MANAGER,

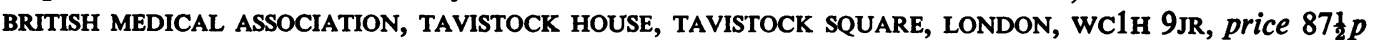

